\title{
Extruded maize flour as texturizing agent in acid-unheated skim milk gels
}

Laura Román ${ }^{1}$, Lara Matia-Merino ${ }^{2}$, Montserrat P. Reguilón ${ }^{1}$, Manuel Gómez ${ }^{1 *}$

${ }^{1}$ Food Technology Area, College of Agricultural Engineering, University of Valladolid, 34004

Palencia, Spain.

${ }^{2}$ Massey Institute of Food Science and Technology, Massey University, Private Bag 11222,

Palmerston North 4442, New Zealand

*Corresponding author e-mail: pallares@iaf.uva.es

Corresponding author telephon number: +34 979108495

\begin{abstract}
Starches have been used to improve the textural properties, substitute fats or increase satiety in yoghurts and acidified milk gels, however studies involving addition of flours are scarce. The objective of this study was to analyze the effect of skim milk substitution by pregelatinized extruded maize flour on the acidification process (changes in $\mathrm{pH}$ and rheology), textural properties, syneresis and microstructure of acidified milk gels (15\% w/w solids). To this end, pregelatinized flour was used to replace 17,33 and $50 \%$ of the skim milk powder. A greater proportion of flour resulted in a faster acidification process and a higher $\mathrm{pH}$ at the gelation point, indicating a faster gelation. The substitution of milk by flour up to $33 \%$ increased the firmness and consistency of the set gel, but these changes were reversed with greater substitution levels due to the lack of a connected protein structure. In addition, a greater syneresis of the gels was observed as the milk content was reduced, an effect that was reversed by increasing the percentage of solids in the mixture.
\end{abstract}

Keywords: yoghurt; acid milk gels; extruded flour; rheology; syneresis 


\section{Introduction}

Yoghurt, a milk-based product consumed for centuries, results from the fermentation of milk by Lactobacillus bulgaricus, Streptococcus thermophilus, and Lactobacillus acidophilus. During fermentation, a progressive acidification takes place as lactic acid is produced, destabilizing the casein micelles as they approach their isoelectric point and allowing the formation of a threedimensional protein network that traps the water. This phenomenon can be mimicked by chemical acid-induced gelation of casein, promoted by the use of a slow acidulant such as glucono- $\delta$-lactone (GDL), which hydrolyses to form gluconic acid (GH), a weak acid that

further dissociates (Chen et al. 1999). This acidification method is frequently used in milk studies as the results highly correlate to the rheological changes occurring in yoghurt when using microbial cultures (Lucey et al. 1998a; Grygorczyk and Corredig 2013), having the advantage of reproducibility and easy manipulation of the rate of acidification.

Starches are known to modify the chemically or microbiologically induced gelation of yoghurts affecting the rheological properties of the final product (Azim et al. 2010a,b; Pang et al. 2015). Thus, native or modified starches can be utilized to improve the texture of stirred yoghurt (Ares et al. 2007) or protein enriched yoghurt (Morell et al. 2015, 2017). Furthermore, starch can also be used as fat replacer (Prasad et al. 2013; Lobato-Calleros et al. 2014) or to increase the expected satiating capacity of the yoghurt (Tarrega et al. 2017). Despite the studies focusing on starch addition on yoghurts, not much research has been conducted on the incorporation of flours, and only Zare et al. (2011) have analyzed the effect of the inclusion of lentil flour. In a similar way to starches, different hydrocolloids (such as pectin, locust bean gum, carrageenan) have also been used to improve the texture of yoghurts and minimize syneresis (Pang et al. 2015; Gyawali and Ibrahim 2016; Nguyen et al. 2017). However, starches are usually added before the pasteurization treatment in order to promote the gelatinization of the starch by the combined action of heat and moisture, with the subsequent retrogradation effect (i.e., increase in viscosity) during cooling. This implies that starch addition causes important rheological changes in yoghurt which are dependent on the nature of the starch used.

If sufficient conditions of moisture and temperature are applied, hydrothermal treatments, such as extrusion of starchy materials, allow the complete pre-gelatinization of starch. Extruded 
flours and starches with most of their starch in gelatinized form, present a high thickening capacity at cold temperature, behaving in a similar way to hydrocolloids, since the viscosity of the aqueous pastes is slightly reduced with the increase of temperature (Martínez et al. 2014a,b). Furthermore, compared to hydrocolloids or chemically modified starches, starchy ingredients treated by extrusion process are not considered additives, allowing for food products with clean labels - highly demanded by consumers (Asioli et al. 2017). Additionally, due to their thickening ability, these extruded flours have already been used to reduce the fat content in cakes (Román et al. 2015a) and mayonnaises (Román et al. 2015b), or to reduce syneresis in sauces (Román et al. 2018a). Nonetheless, to the best of our knowledge, the effect of the addition of these products on the properties of yoghurt or other acidified dairy products has not yet been studied.

The objective of this work was to study the effect of the addition of extruded maize flour on the physical properties of acid-induced skim milk gels. In order to accomplish this goal, changes in $\mathrm{pH}$ and rheology during the gelation process of mixtures made of various ratios of skim milk and extruded flour were analyzed. Textural attributes and syneresis were studied in the yoghurtlike gels obtained, as well as the viscosity of the gels after a stirring step. In addition, microstructural properties of set and stirred gels were evaluated by confocal microscopy.

\section{Materials and methods}

\subsection{Materials}

Hydrothermally modified extruded yellow maize flour (EF) (10.09\% moisture, 6.69\% protein) was provided by Molendum Ingredients (Zamora, Spain). The extrusion treatment was performed with an industrial Bühler Basf single screw extruder (Bühler S.A., Uzwil, Switzerland). The length to diameter (L/D) ratio for the extruder was 20:1. The extrusion was carried out with a further water addition of $12 \%$ at a maximum barrel temperature of $160{ }^{\circ} \mathrm{C}$, a feed rate of $500 \mathrm{~kg} / \mathrm{h}$ and a screw speed of $453 \mathrm{rpm}$. The extruded product was dried by convection air and then ground with a compression roller to a particle size below $200 \mu \mathrm{m}$ (data provided by the company). 
Skim milk powder (SM) was obtained from Nestlé España, S.A. (Esplugues de Llobregat, Barcelona). Glucono-delta-Lactone (GDL) powder was provided by Jungbunzlauer S.A. (Basel, Switzerland).

\subsection{Methods}

\subsubsection{Flour characterization}

Maize extruded flour was characterized according to AACC methods (AACC, 2015) for moisture (44-15.02) and protein content (46-30.01) with a Leco TruSpec device (Leco, St. Joseph, MI, USA). Thermal properties were also measured by DSC analyses as described in Román et al. (2018b). DSC results confirmed that gelatinization was complete (absence of endothermal peak for the melting of amylopectin double helices) after extrusion treatment.

\subsubsection{Sample preparation}

Five different mixtures were prepared using various skim milk-extruded flour ratios: Control (15\% SM), 12.5\% SM-2.5\% EF, 10\% SM-5\% EF, 7.5\% SM-7.5\% EF and 15\% SM-5\% EF. The amounts of the ingredients used are shown in Table 1. The concentration of total solids in all the samples was 15\%, except for the sample at 15\% SM-5\% EF (with final $20 \%$ total solids) where the effect of the addition of EF was studied instead of substituting the SM by the EF. Skim milk powder was reconstituted in distilled water at $30^{\circ} \mathrm{C}$ for 120 min under continuous stirring. The corresponding amounts of flour were added to these protein solutions and dispersed for 15 mins. The $\mathrm{pH}$ values were measured with a pH-meter (GLP21 Crison, Barcelone, Spain) at the end of the mixing period, and the $\mathrm{pH}$ of each sample was adjusted to $6.66( \pm 0.01)$ with $\mathrm{NaOH}$. GDL was added to these mixtures at a level of $2 \%(\mathrm{wt} / \mathrm{wt})$, mixing thoroughly for $2.5 \mathrm{~min}$ and subsequently incubating the samples at $30^{\circ} \mathrm{C}$ for 6 hours. This level of GDL addition was chosen to induce a drop in $\mathrm{pH}$ from neutral to $c a$. $\mathrm{pH} 4.8$ after $6 \mathrm{~h}$ of acidification. After this period, the acid milk gels, denoted as "set" gels, were stored for $48 \mathrm{~h}$ at $4^{\circ} \mathrm{C}$ before testing. For the production of "stirred" milk gels, the gels were stirred after $24 \mathrm{~h}$ of cold storage during 45 seconds at speed $1(60 \mathrm{rpm})$ in a 5KSM150 Kitchen-Aid Artisan (KitchenAid, St. Joseph, Michigan, USA). After stirring, the samples were stored at $4^{\circ} \mathrm{C}$ for another $24 \mathrm{~h}$ to ensure gel 
stabilization before testing. Each of the set and stirred gels - both types relevant in the European market and therefore interesting to study - were produced in duplicate.

\subsection{3 pH monitoring after GDL addition}

Changes in $\mathrm{pH}$ over time after GDL addition were monitored using a glass electrode and a standard $\mathrm{pH}$ meter (GLP21 Crison, Barcelona, Spain). The $\mathrm{pH}$ values were recorded at a temperature of $30{ }^{\circ} \mathrm{C}$ between 3 and 360 min at 1 min intervals. The $\mathrm{pH}$ evolution was recorded in duplicate.

\subsubsection{Rheological properties}

After GDL addition to the milk-flour mixtures, thorough mixing was carried out for 2.5 min and the samples were placed into the rheometer to follow the gelation in situ starting from minute 3 in all cases. The development of the viscoelastic properties of the acid milk gels was monitored by dynamic oscillatory shear measurements, performed on a controlled-stress rheometer (Haake RheoStress 1, Thermo Fischer Scientific, Scheverte, Germany) using a concentric cylinder system (Z34 DIN Ti) and with a Phoenix II P1-C25P control temperature unit and RheoWin 4 Job Manager software for analysis. The samples were covered with Panreac vaseline oil (Panreac Química S.A., Castellar del Vallés, Spain) to avoid drying. Changes in the viscoelastic properties were evaluated by monitoring the storage or elastic modulus $\left(G^{\prime}\right)$ and loss or viscous modulus $\left(G^{\prime \prime}\right)$ for $180 \mathrm{~min}$ at $30^{\circ} \mathrm{C}$ and at a constant shear strain of $0.5 \%$ within the linear region and a frequency of $1 \mathrm{~Hz}$.

Viscosity of the stirred gels was measured after 48 hours cold storage. Gel samples were loaded with a plastic spoon into the rheometer, on a concentric cylinder system (Z34 DIN Ti) and allowed to equilibrate at $6^{\circ} \mathrm{C}$ for $2 \mathrm{~min}$ before pre-shearing at $100 \mathrm{~s}^{-1}$ for $1 \mathrm{~min}$ to eliminate any shear history. An up and down shear rate profile from $0.1 \mathrm{~s}^{-1}$ to $500 \mathrm{~s}^{-1}$ was set up to obtain steady apparent shear viscosity readings. All rheological tests were carried out in duplicate.

\subsubsection{Texture and syneresis}

Set gels were formed in cylindrical plastic containers $(65 \mathrm{~mm}$ diameter and $60 \mathrm{~mm}$ height $)$ as described in 2.2.1. Texture analysis was carried out after $48 \mathrm{~h}$ cold storage at $4^{\circ} \mathrm{C}$ using a 
TA.XT2i Texture Analyzer (Stable Micro Systems Ltd., Surrey, UK) equipped with Texture Expert version 1.0 software for Windows. A $5 \mathrm{~kg}$ load was used for force calibration. A back extrusion essay was performed using a $50 \mathrm{~mm}$-diameter cylindrical probe at a constant crosshead velocity of $1 \mathrm{~mm} \mathrm{~s}^{-1}$ to a sample depth of $30 \mathrm{~mm}$, followed by a return to the original position. Four parameters were extracted from the force-time curve: firmness (maximum positive force registered), consistency (positive area), adhesiveness (minimum negative force registered) and viscosity index (negative area).

Syneresis was also assessed after cold storage of the gels at $4{ }^{\circ} \mathrm{C}$ for $48 \mathrm{~h}$. Quantities of $15.00 \mathrm{~g}$ $\left(\mathrm{W}_{0}\right)$ of the stirred gels were placed in $50 \mathrm{ml}$ falcon centrifuge tubes - the set gels were formed in them directly - and centrifuged for $10 \mathrm{~min}$ at $2500 \mathrm{rpm}$. The supernatant was then removed and weighed $\left(\mathrm{W}_{1}\right)$. Syneresis was calculated as follows:

$\%$ Syneresis $=\left(\mathrm{W}_{1} / \mathrm{W}_{0}\right) \times 100$

All tests were done in duplicate in set and stirred gels.

\subsubsection{Confocal Microscopy}

A Leica SP5 DM6000B confocal laser scanning microscopy (Leica Lasertechnik GmbH, Heidelberg, Germany) was used to examine the gel microstructures, with a $63 \mathrm{x}$ oil immersion objective. The milk-flour mixtures were stained with fluorescent dye Rhodamine B $(0.05 \% \mathrm{w} / \mathrm{v})$ prior to acidification in order to label the protein phase. After GDL addition, $0.5 \mathrm{ml}$ aliquots were placed into laboratory-made welled slides and a cover slide was then placed over the sample before incubation at $30^{\circ} \mathrm{C}$ for $6 \mathrm{~h}$. Samples were then stored at $4^{\circ} \mathrm{C}$ for $48 \mathrm{~h}$ before visualization (set gels). Stirred gels were also dyed, formed and stored in the same way but placed on the wells just before visualization. Images were scanned at 10-15 $\mu \mathrm{m}$ below the coverslip. For Rhodamine B fluorescence detection the parameters were as follows: Ex: $568 \mathrm{~nm}$, Em: 571-625 nm. Experiments were done in duplicate.

\subsubsection{Statistical analyses}

Differences between the textural attributes of set gels and between the syneresis properties of set and stirred gels were studied by analysis of variance (one-way ANOVA). Fisher's least 
significant difference (LSD) was used to describe means with 95\% confidence intervals. The statistical analysis was performed with the Statgraphics Centurion XVII (StatPoint Technologies Inc, Warrenton, USA).

\section{Results and Discussion}

\subsection{Evolution of $\mathrm{pH}$ and rheological properties}

The evolution of the $\mathrm{pH}$ and the rheology of the mixtures after the addition of GDL are depicted in Figures 1 and 2, respectively. The curve for the $\mathrm{pH}$ evolution shows a rapid initial drop, within the first two hours, reaching almost plateau values after $6 \mathrm{~h}$ of acidification between $\mathrm{pH}$ 4.6 for the control, and $\mathrm{pH} 4.16$ for the sample with the lowest SM concentration (7.5\%). It is clear that as the content of skim milk (SM) decreases and that of extruded flour (EF) increases, the rate of acidification is accelerated, and the final $\mathrm{pH}$ of the gel is lower. Previous studies observed no effect (Williams et al. 2003, Zuo et al. 2008; Azim et al. 2010a) or a minimum effect (Oh et al. 2007) on the decrease of $\mathrm{pH}$ during the acidification process of milk, upon incorporation of starches; probably due to the lower amounts of starch incorporated (less than $1.5 \%)$. The fact that in our study, the sample containing similar amount of SM to the control (15\%) plus the highest amount of EF (5\%) showed a completely similar rate of acidification to the control sample (only 15\% SM) clearly demonstrates that the flour has no effect on the rate of acidification. The reason for the greater decrease in $\mathrm{pH}$ with the reduction of the SM content while keeping the amount of GDL constant is likely to be due to the lower buffering effect of the milk proteins (Salaun et al. 2005) as their concentrations decrease in the mixtures.

Regarding the rheological evolution of $G^{\prime}$ and $G^{\prime \prime}$ (Figure 2), both moduli showed a lag phase in which the values of $G^{\prime}$ and $G^{\prime \prime}$ did not exceed $0.1 \mathrm{~Pa}$ for the control, and $1 \mathrm{~Pa}$ in the case of the mixture with the highest percentage of extruded flour, indicating that the milk in the mixture remained liquid. The sudden rise in these values that indicates the gelation point (see below), followed by a steady increase of moduli, clearly reaching plateau values at the lowest SM concentration (7.5\%), shows similar acid-induced milk gelation profiles to those found in other studies dealing with GDL-induced skim milk gels (Lucey et al. 1998a; Oh et al. 2007, 2011). The very low $G^{\prime}$ and $G^{\prime \prime}$ final values and delayed gelation of our control sample- compared to other studies - are likely to be attributed to the fact that skim milk was not previously heated. 
Based on previous studies it is known that acid gels made from preheated skim milk (SM) have higher storage modulus than those made from unheated SM, being the heat-induced noncovalent and disulphide interactions between denatured whey proteins and $\kappa$-casein responsible for this observation (Lucey et al. 1997, 1998b, 1999; Graveland-Bikker and Anema 2003; Oh et al. 2007).

It is clear from Figure 2 that as the SM content was reduced and the EF content was increased, faster gelation was observed (faster increase of moduli and cross-over) and higher values of $G^{\prime}$ and $G^{\prime \prime}$ were obtained after acidification. This effect is very clear for mixtures with $0,2.5$ and $5 \% \mathrm{EF}$. pH at gelation time was determined for each sample as the $\mathrm{pH}$ at which $G^{\prime}$ values cross over $G^{\prime \prime}$ values (Figure 3). The $\mathrm{pH}$ at the gelation point (time $\sim 116 \mathrm{~min}$ ) increased from $\mathrm{pH} 5.06$ in the absence of flour (control sample) to $\sim \mathrm{pH} 5.31$ (time $\sim 23 \mathrm{~min}$ ) with the greatest amount of flour and lowest amount of milk (7.5\% SM-7.5\% EF) (Figure 2). It has been previously shown that a faster rate of acidification of milk at $30{ }^{\circ} \mathrm{C}$ (as it happens in the present study), results in greater viscoelasticity $\left(G^{\prime}, G^{\prime \prime}\right)$ of the network with the $\mathrm{pH}$ at gelation being largely independent on this rate (Horne 2001). The fact that a reduction in the gelation time and an increase in the $\mathrm{pH}$ at gelation have already been observed by Oh et al. (2007) for acid milk gels with $1.5 \%$ starch added — where the rate of acidification was similar — confirms that in the presence of starch, the $\mathrm{pH}$ needed for the gelation process to occur (casein-starch network formation) is reached sooner. The gelation rate was also increased upon addition of flour to the milk from $~ 99$ min ( $\mathrm{pH} 5.14$ ) for $15 \% \mathrm{SM}-5 \% \mathrm{EF}$ to $116 \mathrm{~min}(\mathrm{pH} 5.06$ ) for $15 \% \mathrm{SM}$, highly likely to do with an increase in the total solids from $15 \%$ to $20 \%$ TS. The fact that a still faster gelation, with greater viscoelasticy occurs at a lower total solid content (10\% SM-5\% EF) compared to the highest (15\% SM-5\% EF) indicates an optimum flour/milk ratio for the formation of a network in mixed systems.

As for the higher values of $G^{\prime}$ and $G^{\prime \prime}$ obtained when substituting SM with EF, these are in agreement with previous observations (Oh et al. 2007). However, for this increase to occur the starch needs to be gelatinized, which is achieved by heating the milk-starch mixtures prior to acidification. If this heating does not occur, or its conditions are not sufficient to promote starch gelatinization, the increase in the viscoelastic moduli of the formed gel is not observed (Oh et al. 2007; Zuo et al. 2008). In our case this previous heating is not necessary, since the starch present 
in the extruded maize flours is completely gelatinized having the capacity to absorb water and thicken at room temperature (Martinez et al. 2014a, b). In fact, higher values of $G^{\prime}$ and $G^{\prime \prime}$ were also observed at the beginning of the curve before gelation with increasing EF levels. Other than the thickening effect of pregelatinized starch (Hansen 1993), and a faster rate of acidification when substituting protein by starch (Horne 2001), the higher viscoelastic moduli can also be ascribed to interactions between starch and casein, as previously demonstrated with modified starches (Sun et al. 2016). These authors used Fourier transform infrared spectroscopy (FTIR) and differential scanning calorimetry (DSC) to investigate the role of hydrogen bonds between modified starches and casein. They deduced that possible electrostatic adhesion, steric stabilization and hydrogen bonds took place in the mixed systems. However in the present system, the starch has not undergone any chemical modification (only gelatinization) so it is not expected to be charged. Noisuwan et al. (2007) have also suggested that adsorption of the milk proteins to starch granules is possible through hydrophobic interactions. Overall we can only hypothesize a possible interaction between the milk proteins and the gelatinized starch present in the flour.

The mixture with the highest content of EF and lowest level of SM (7.5\% SM-7.5\% EF) did not follow the trend; this sample presented the fastest gelation among all the mixtures, but the increase in the values of $G^{\prime}$ and $G^{\prime \prime}$ was much lower than in the rest of the mixtures, being the final values similar to those of the control sample. This seems to indicate that a minimum level of milk proteins is necessary for the formation of a strong three-dimensional network where the starch and the other components of the flour can be integrated, and where interactions between protein and starch through possible hydrogen and/or hydrophobic bonds may be formed. A possible threshold level for the acid-induced milk protein network to be formed maybe around 9\% wt/wt solids in milk (Tamime and Robinson, 1999) which would explain the extremely weak network formed when only using 7.5\% SM. In general, an enrichment with milk proteins positively affects the characteristics of acid milk gels (Damin et al. 2009).

\subsection{Textural attributes and syneresis of set and stirred gels}

Regarding the texture of the final gel, an increase in firmness, consistency and adhesiveness values as well as in viscosity index was found when the SM content was reduced and the EF 
content was increased, up to values of SM of $10 \%$ (Table 2). In contrast, when the SM content was reduced to $7.5 \%$, there was a sudden fall in those values. The higher values of firmness and consistency and the sudden drop below 10\% SM are in agreement with the values found for the viscoelastic moduli (Figure 2). These results are also consistent with those observed in previous studies with the incorporation of modified starches previously gelatinized by heating the milkstarch mixture (Sandoval-Castilla et al. 2004; Pang et al. 2015). As explained in the section above, the strengthening of the network in the presence of pregelatinized starch can be caused by a combination of factors. It is also known that starch can act as a filler agent in a continuous protein matrix and that both polymers can form a biphasic gelled system with short plastic texture and high viscosity (Ledward 1993; Sandoval-Castilla et al. 2004). However, for this matrix to be created, a minimum protein content seems to be necessary, above which the effect of other ingredients (in this case, the flour components) can become obvious. Clearly, insufficient protein levels were evident at 7.5\% SM resulting in the weakest/ least firm gels. In fact, $7.5 \%$ SM- 7.5\% EF gel behave like a soft and pourable system (long texture), which did not exhibit the properties of a true set gel. The increase in the adhesiveness of the gels with extruded flour, already observed by Pang et al (2015) with modified starches, is typical of pregelatinized starches and can be enhanced if starch is fragmented (Amelia and BeMiller 2009), as it happens after extrusion process (Kowalski et al. 2018).

The syneresis of set and stirred gels is summarized in Table 2. For the set gels, the syneresis follows a similar trend to that reported on the firmness of the gel, increasing, as the SM content decreases, but decreasing significantly between the mixtures with SM content of 10 and 7.5\%. Therefore it seems that there is a point between the mixtures 10\% SM-5\% EF and 7.5\% SM7.5\% EF in which the behavior of the gels changes. This trend is in agreement with the results reported by Amaya-Llano et al. (2008) with the addition of hydrolyzed maize starch. However, Nguyen et al. (2017) observed that the incorporation of modified starch (hydroxypropyl starch phosphate derived from waxy maize) could reduce the syneresis, which indicates that the effect of the starch will depend on the type of starch and its modification. Similarly, San MartínMartínez et al. (2004) reported that a higher degree of substitution in starch phosphates brought about yoghurts with higher stability and lower syneresis. In our study, it seems that the reduction of the milk protein content is more important than the increase in the flour, seriously affecting the water holding capacity of the final gels. In this sense, one of the causes of the high syneresis 
with the increase in the percentage of flour could be the hydrolysis that the starches undergo in acidic conditions (Wang and Copeland 2015). In fact, in the works of San Martín-Martínez et al. (2004) and Nguyen et al. (2017) a reduction of the syneresis was achieved by modifying the starches and conferring them resistance to low $\mathrm{pH}$ conditions. Another reason for the highest syneresis with the inclusion of EF and reduction in the SM content could be related to a disruptive effect of the extruded flour to the more limited protein network, interfering with the casein aggregation and strand network formation (a faster gelation with EF addition/SM reduction may result in a less ordered/more unconnected aggregated protein). Clearly, the lowest values of syneresis were shown with the highest concentrations of SM. When adding EF to the highest SM (15\% SM-5\% EF) no significant differences were observed between the syneresis values of the gel of this mixture compared to the control, being much lower than those of the $10 \%$ SM-5\% EF mixture, which would reinforce the idea of the importance of a minimum percentage of dairy solids to reduce the syneresis. Similar trends were found in the stirred gels, with the difference being the higher levels of syneresis compared to set gels. For the syneresis values of the stirred yoghurts, a clear increase in water release was visible when the amount of SM was reduced, but not when EF was added, since the values of the 15\% SM-5\% EF mixture did not show significant differences compared to the control. Therefore, the values of syneresis of the set and stirred gels follow a similar trend except for what happens with the $7.5 \%$ SM$7.5 \%$ EF mixture, which in the case of the set gels presents a syneresis decrease. This decrease can be explained by the pourable structure of the $7.5 \%$ SM-7.5\% EF set gel, which did not behave like an actual set gel, and its almost liquid texture may make difficult water phase separation from the matrix.

As seen in Figure 4, apparent viscosity of stirred gel systems exhibited a thixotropic flow behavior; as shear rate was increased, the disruption of the protein network, together with the subsequent alignment of protein aggregates with the flow, yielded decreasing viscosity. This viscosity did not recover, as the values were lower when shearing down the milk gels - therefore exhibiting hysteresis. Higher apparent viscosity was observed with higher contents of extruded flours in the mixture (up curve generated by increasing shear rate-filled symbols), presenting the $12.5 \% \mathrm{SM}-2.5 \% \mathrm{EF}, 10 \% \mathrm{SM}-5 \% \mathrm{EF}$ and $15 \% \mathrm{SM}-5 \% \mathrm{EF}$ mixtures a similar profile to the control at higher shear rates. Other authors have observed a similar behavior with the incorporation of starches, both modified and native (Cui et al. 2014, Lobato-Caballero et al. 
2014), which may be related to the thickening power of the starch present in the flour, once gelatinized. In fact, Zou et al. (2008) observed that this increase in viscosity in samples containing starch was only visible from a heating at $70-80{ }^{\circ} \mathrm{C}$. However, when the content in extruded flour is very high, as in the $7.5 \% \mathrm{SM}-7.5 \% \mathrm{EF}$ mixture, a drop in viscosity occurs, being $7.5 \%$ SM-7.5\% EF mixture similar to the control, and confirming the importance of the presence of a minimum amount of SM to form an adequate network. Regarding the down curveempty symbols (generated when the shear rate is reduced back to the original values), higher apparent viscosity values were observed for the control sample, and for samples with lower amounts of EF, indicating a greater strength of the gel that can resist high shear conditions. Conversely, gels with the highest incorporation of EF (7.5\% SM-7.5\% EF) or those with the highest solids content (15\% SM-5\% EF) have the lowest apparent viscosity values, with a remarkable degree of hysteresis for the later gel. In the presence of high amounts of EF, a greater drop in viscosity after shearing the gels could indicate the formation of a more heterogeneous and less cohesive initial protein network.

\subsection{Microstructure of mixed gels}

Regarding the gel microstructures observed with increasing amount of flour, Figure 5 shows the protein structures dyed with Rhodamine B (in white) with the dark areas being the water phase containing mainly gelatinized starch from the flour. A very dense, interconnected and homogenous network with relatively small pore size was observed for the control set sample at 15\% SM (Fig. 4a), clearly showing greater pores when the casein network was broken after stirring (Fig. 4b). Similar protein networks have been earlier reported (Lucey et al. 1999; MatiaMerino and Singh 2007). When increasing the flour content (and decreasing the protein)$12.5 \% \mathrm{SM}-2.5 \% \mathrm{EF}$ and 10\% SM-5\% EF samples-larger average pore size was detected, due to the greater starch content, but the protein seemed to aggregate into thicker clusters that appeared to have a lower degree of interconnectivity in the stirred samples, confirming more heterogeneous and less cohesive networks in the presence of the flour; this could also account for the greater degree of syneresis in the presence of flour observed in what appear to be "stronger gels" (higher viscoelasticity and firmness). It is noteworthy that 7.5\% SM-7.5\% EF stirred gel did not show the appearance of a connected network, confirming the weaker nature of this gel, and the highest syneresis. The sample with a similar level of protein to the control, but 
with the highest amount of starch (15\% SM-5\% EF) showed this clustering of protein to a greater extent, though the syneresis levels were similar to the control, so this correlation is not straight forward. Oh et al., (2007) found that the density of the protein network increased with an increase in the potato starch level used, also detecting individual swollen granules as dark globules embedded in the protein network, similarly observed with rice starch (Zuo et al, 2008); in our case, no obvious individual starch granules are present, probably because the extrusion process entirely disrupts the granules since complete gelatinization was achieved.

\section{Conclusions}

This study shows that the substitution of milk by pregelatinized flour in the making of acidified gels can improve their texture, increasing the firmness of the set gels, and the consistency and apparent viscosity of the stirred gels. Although positive results are seen in the rheological behavior of acidified gels, attention must be paid to the level of flour replacement since an increased syneresis is observed-effect that can be reversed by increasing the percentage of solids in the mixture. In addition, a minimum amount of milk is necessary to form a homogeneous interconnected network. Pregelatinized extruded flour helped in the development of a firmer network structure up to a critical flour concentration, which may cause interferences in the network connection.

\section{Acknowledgements}

The authors acknowledge the financial support of the European Regional Development Fund (FEDER) and the Spanish Ministry of Economy and Competitiveness (Project AGL2014-52928C2). We would like to acknowledge Matthew Savoian and Niki Minards at the Manawatu Microscopy Imaging Centre at Massey University for the help provided on the acquisition of the confocal images. The authors are also grateful to Molendum Ingredients, for supplying the raw materials. Laura Roman would like to thank the University of Valladolid for her pre-doctoral fellowship. 


\section{References}

AACC (2015). Approved methods of the American Association of Cereal Chemists, Methods 44-15.02 (moisture), 46-30.01 (protein), 11th ed. St. Paul, Minnesota: American Association of Cereal Chemists.

Amaya-Llano, S. L., Martínez-Alegría, A. L., Zazueta-Morales, J. J., \& Martinez-Bustos, F. (2008). Acid thinned jicama and maize starches as fat substitute in stirred yogurt. LWT-Food Science and Technology, 41, 1274-1281.

Amelia, I., \& BeMiller, J. N. (2009). Preparation of nonfragmented, completely amorphous, pregelatinized maize starches and determination of the effects of fragmentation on the adhesiveness of their pastes. Starch-Starke, 61, 696-701.

Ares, G., Goncalvez, D., Perez, C., Reolon, G., Segura, N., Lema, P., \& Gambaro, A. (2007). Influence of gelatin and starch on the instrumental and sensory texture of stirred yogurt. International Journal of Dairy Technology, 60, 263-269.

Asioli, D., Aschemann-Witzel, J., Caputo, V., Vecchio, R., Annunziata, A., Næs, T., \& Varela, P. (2017). Making sense of the "clean label" trends: A review of consumer food choice behavior and discussion of industry implications. Food Research International, 99, 58-71.

Azim, Z., Alexander, M., Koxholt, M., \& Corredig, M. (2010a). Influence of cross-linked waxy maize starch on the aggregation behavior of casein micelles during acid-induced gelation. Food Biophysics, 5, 227-237.

Azim, Z., Corredig, M., Koxholt, M., \& Alexander, M. (2010b). Sol gel transitions during acid gelation of milk containing modified waxy maize starch. Differences between chemical and bacterial acidification measured using rheological and spectroscopic techniques. International Dairy Journal, 20, 785-791.

Chen, J. S., Dickinson, E., \& Edwards, M. (1999). Rheology of acid-induced sodium caseinate stabilized emulsion gels. Journal of Texture Studies, 30, 377-396.

Cui, B., Lu, Y. M., Tan, C. P., Wang, G. Q., \& Li, G. H. (2014). Effect of cross-linked acetylated starch content on the structure and stability of set yoghurt. Food Hydrocolloids, 35, 576-582.

Damin, M. R., Alcantara, M. R., Nunes, A. P., \& Oliveira, M. N. (2009). Effects of milk supplementation with skim milk powder, whey protein concentrate and sodium caseinate on 
acidification kinetics, rheological properties and structure of nonfat stirred yogurt. LWT-Food Science and Technology, 42, 1744-1750.

Graveland-Bikker, J. F., \& Anema, S. G. (2003). Effect of individual whey proteins on the rheological properties of acid gels prepared from heated skim milk. International Dairy Journal, 13, 401-408.

Grygorczyk, A., \& Corredig, M. (2013). Acid induced gelation of soymilk, comparison between gels prepared with lactic acid bacteria and glucono-delta-lactone. Food Chemistry, 141, 17161721.

Gyawali, R., \& Ibrahim, S. A. (2016). Effects of hydrocolloids and processing conditions on acid whey production with reference to Greek yogurt. Trends in Food Science \& Technology, 56, 61-76.

Hansen, P. M. T. (1993). Food hydrocolloids in the dairy industry. In K. Nishinari and E. Doi (Eds.), Food hydrocolloids (pp. 211-224). New York: Springer.

Horne, D. S. (2001). Factors influencing acid-induced gelation of skim milk. In E. Dickinson and R. Miller (Eds.), Food colloids: Fundamentals of formulation (pp. 345-351). Cambridge: Royal Society of Chemistry.

Kowalski, R. J., Hause, J. P., Joyner, H., \& Ganjyal, G. M. (2018). Waxy flour degradation Impact of screw geometry and specific mechanical energy in a co-rotating twin screw extruder. Food Chemistry, 239, 688-696.

Ledward, D. A. (1993). Creating textures from mixed biopolymer systems. Trends in Food Science \& Technology, 4, 402-405.

Lobato-Calleros, C., Ramirez-Santiago, C., Vernon-Carter, E. J., \& Alvarez-Ramirez, J. (2014). Impact of native and chemically modified starches addition as fat replacers in the viscoelasticity of reduced-fat stirred yogurt. Journal of Food Engineering, 131, 100-115.

Lucey, J. A., Tamehana, M., Singh, H., \& Munro, P. A. (1998a). A comparison of the formation, rheological properties and microstructure of acid skim milk gels made with a bacterial culture or glucono-delta-lactone. Food Research International, 31, 147-155.

Lucey, J. A., Tamehana, M., Singh, H., \& Munro, P. A. (1998b). Effect of interactions between denatured whey proteins and casein micelles on the formation and rheological properties of acid skim milk gels. Journal of Dairy Research, 65, 555-567. 
Lucey, J. A., Teo, C. T., Munro, P. A., \& Singh, H. (1997). Rheological properties at small (dynamic) and large (yield) deformations of acid gels made from heated milk. Journal of Dairy Research, 64, 591-600.

Lucey, J. A., Munro, P. A., \& Singh, H. (1999). Effects of heat treatment and whey protein addition on the rheological properties and structure of acid skim milk gels. International Dairy Journal, 9, 275-279.

Martínez, M. M., Calviño, A., Rosell, C. M., \& Gómez, M. (2014a). Effect of different extrusion treatments and particle size distribution on the physico-chemical properties of rice flour. Food and Bioprocess Technology, 7, 2657-2665.

Martínez, M. M., Rosell, C. M., \& Gómez, M. (2014b). Modification of wheat flour functionality and digestibility through different extrusion conditions. Journal of Food Engineering, 143, 74-79.

Matia-Merino, L., \& Singh, H. (2007). Acid-induced gelation of milk protein concentrates with added pectin: Effect of casein micelle dissociation. Food Hydrocolloids, 21, 765-775.

Morell, P., Chen, J. S., \& Fiszman, S. (2017). The role of starch and saliva in tribology studies and the sensory perception of protein-added yogurts. Food \& Function, 8, 545-553.

Morell, P., Hernando, I., Llorca, E., \& Fiszman, S. (2015). Yogurts with an increased protein content and physically modified starch: rheological, structural, oral digestion and sensory properties related to enhanced capacity. Food Research International, 70, 64-73.

Noisuwan, A., Hemar, Y., Bronlund, J. E., Wilkinson, B., \& Williams, M. A. K. (2007). Viscosity, swelling and starch leaching during the early stages of pasting of normal and waxy rice starch suspensions containing different milk protein ingredients. Starch-Stärke, 59(8), 379387.

Nguyen, P. T. M., Kravchuk, O., Bhandari, B., \& Prakash, S. (2017). Effect of different hydrocolloids on texture, rheology, tribology and sensory perception of texture and mouthfeel of low-fat pot-set yoghurt. Food Hydrocolloids, 72, 90-104.

Oh, H. E., Anema, S. G., Wong, M., Pinder, D. N., \& Hemar, Y. (2007). Effect of potato starch addition on the acid gelation of milk. International Dairy Journal, 17, 808-815.

Pang, Z. H., Deeth, H., \& Bansal, N. (2015). Effect of polysaccharides with different ionic charge on the rheological, microstructural and textural properties of acid milk gels. Food Research International, 72, 62-73. 
Prasad, L. N., Sherkat, F., \& Shah, N. P. (2013). Influence of galactooligosaccharides and modified waxy maize starch on some attributes of yogurt. Journal of Food Science, 78, M77M83.

Román, L., Gomez, M., Hamaker, B. R., \& Martinez, M. M. (2018b). Shear scission during extrusion diminishes inter-molecular interactions of starch molecules during storage. Journal of Food Engineering, 238, 134-140.

Román, L., Martínez, M. M., \& Gómez, M. (2015b). Assessing of the potential of extruded flour paste as fat replacer in $\mathrm{O} / \mathrm{W}$ emulsion: A rheological and microstructural study. Food Research International, 74, 72-79.

Román, L., Reguilón, M., \& Gómez, M. (2018a). Physicochemical characteristics of sauce model systems: Influence of particle size and extruded flour source. Journal of Food Engineering, 219, 93-100.

Román, L., Santos, I., Martínez, M. M., \& Gómez, M. (2015a). Effect of extruded wheat flour as a fat replacer on batter characteristics and cake quality. Journal of Food Science and Technology-Mysore, 52, 8188-8195.

Salaun, F., Mietton, B., \& Gaucheron, F. (2005). Buffering capacity of dairy products. International Dairy Journal, 15, 95-109.

Sandoval-Castilla, O., Lobato-Calleros, C., Aguirre-Mandujano, E., \& Vernon-Carter, E. J. (2004). Microstructure and texture of yogurt as influenced by fat replacers. International Dairy Journal, 14, 151-159.

San Martin-Martinez, E., Aguilar-Mendez, M. A., Espinosa-Solares, T., Pless, R. C., \& Quintana, Z. D. (2004). Starch phosphates produced by extrusion: Physical properties and influence on yogurt stability. Starch-Starke, 56, 199-207.

Sun, N. X., Liang, Y., Yu, B., Tan, C. P., \& Cui, B. (2016). Interaction of starch and casein. Food Hydrocolloids, 60, 572-579.

Tamime, A. Y., \& Robinson, R.K. (1999). Yoghurt. Science and Technology. Cambridge: Woodhead Publishing Ltd.

Tarrega, A., Marcano, J., \& Fiszman, S. (2016). Yogurt viscosity and fruit pieces affect satiating capacity expectations. Food Research International, 89, 574-581.

Wang, S. J., \& Copeland, L. (2015). Effect of acid hydrolysis on starch structure and functionality: A review. Critical Reviews in Food Science and Nutrition, 55, 1079-1095. 
Williams, R. P. W., Glagovskaia, O., \& Augustin, M. A. (2003). Properties of stirred yogurts with added starch: Effects of alterations in fermentation conditions. Australian Journal of Dairy Technology, 58, 228-232

Zare, F., Boye, J. I., Orsat, V., Champagne, C., \& Simpson, B. K. (2011). Microbial, physical and sensory properties of yogurt supplemented with lentil flour. Food Research International, 44, 2482-2488.

Zuo, J. Y., Hemar, Y., Hewitt, S., \& Saunders, A. (2008). Effect of the extent of pasting on the dynamic rheological properties of acidified skim milk gels containing normal rice starch. Food Hydrocolloids, 22, 1567-1573.

Table 1. Composition of the mixed milk protein-flour acid gels

\begin{tabular}{lccccc}
\hline & $\begin{array}{c}\text { Total } \\
\text { solids }\end{array}$ & $\begin{array}{c}\text { Skim milk } \\
\text { powder }(\boldsymbol{\%})\end{array}$ & $\begin{array}{c}\text { Flour } \\
(\boldsymbol{\%})\end{array}$ & $\begin{array}{c}\text { GDL } \\
(\boldsymbol{\%})\end{array}$ & $\begin{array}{c}\text { Distilled } \\
\text { water }\end{array}$ \\
\hline Control sample & 15 & 15 & 0 & 2 & 83 \\
$\mathbf{1 2 . 5 \%}$ SM-2.5\% & 15 & 12.5 & 2.5 & 2 & 83 \\
$\mathbf{1 0 \%}$ SM-5\% EF & 15 & 10 & 5 & 2 & 83 \\
$\mathbf{7 . 5 \%}$ SM-7.5\% & 15 & 7.5 & 7.5 & 2 & 83 \\
$\mathbf{1 5 \%}$ SM-5\% EF & 20 & 15 & 5 & 2 & 78 \\
\hline
\end{tabular}

Table 2. Texture attributes of set gels and syneresis properties of set and stirred gels

\begin{tabular}{lcccccc}
\hline \multicolumn{1}{c}{ Sample } & $\begin{array}{c}\text { Firmness } \\
(\mathbf{m N})\end{array}$ & $\begin{array}{c}\text { Consistency } \\
(\mathbf{m N} \cdot \mathbf{s})\end{array}$ & $\begin{array}{c}\text { Adhesiveness } \\
(\mathbf{m N})\end{array}$ & $\begin{array}{c}\text { Viscosity } \\
\text { Index }(\mathbf{m N} \cdot \mathbf{s})\end{array}$ & $\begin{array}{c}\text { Syneresis Set } \\
\text { gel }(\%)\end{array}$ & $\begin{array}{c}\text { Syneresis Stirred } \\
\text { gel }(\%)\end{array}$ \\
\hline Control & $2271 \mathrm{~b} \pm 32$ & $5,64 \times 10^{4} \mathrm{~b} \pm 0.23$ & $950 \mathrm{a} \pm 53$ & $2167 \mathrm{a} \pm 77$ & $4.35 \mathrm{ab} \pm 0.12$ & $18.17 \mathrm{a} \pm 0.38$ \\
$12.5 \% \mathrm{SM}-2.5 \% \mathrm{EF}$ & $4154 \mathrm{~d} \pm 233$ & $10,72 \times 10^{4} \mathrm{~d} \pm 0.68$ & $2207 \mathrm{~b} \pm 330$ & $4334 \mathrm{~b} \pm 306$ & $8.29 \mathrm{c} \pm 0.82$ & $27.01 \mathrm{~b} \pm 0.84$ \\
$10 \% \mathrm{SM}-5 \% \mathrm{EF}$ & $4726 \mathrm{e} \pm 157$ & $10,82 \times 10^{4} \mathrm{~d} \pm 0.15$ & $2394 \mathrm{bc} \pm 185$ & $5607 \mathrm{c} \pm 462$ & $22.70 \mathrm{~d} \pm 0.70$ & $31.23 \mathrm{c} \pm 2.76$ \\
$7.5 \% \mathrm{SM}-7.5 \% \mathrm{EF}$ & $1287 \mathrm{a} \pm 71$ & $3,27 \times 10^{4 \mathrm{a}} \pm 0.14$ & $746 \mathrm{a} \pm 84$ & $1711 \mathrm{a} \pm 54$ & $3.23 \mathrm{a} \pm 0.89$ & $43.26 \mathrm{~d} \pm 0.67$ \\
$15 \% \mathrm{SM}-5 \% \mathrm{EF}$ & $3459 \mathrm{c} \pm 161$ & $9,31 \times 10^{4} \mathrm{c} \pm 0.87$ & $2811 \mathrm{c} \pm 557$ & $6021 \mathrm{c} \pm 245$ & $4.93 \mathrm{~b} \pm 1.46$ & $15.39 \mathrm{a} \pm 3.22$ \\
\hline
\end{tabular}

Values \pm standard deviations with different letters in the same column are significantly different with $p<0.05$ 


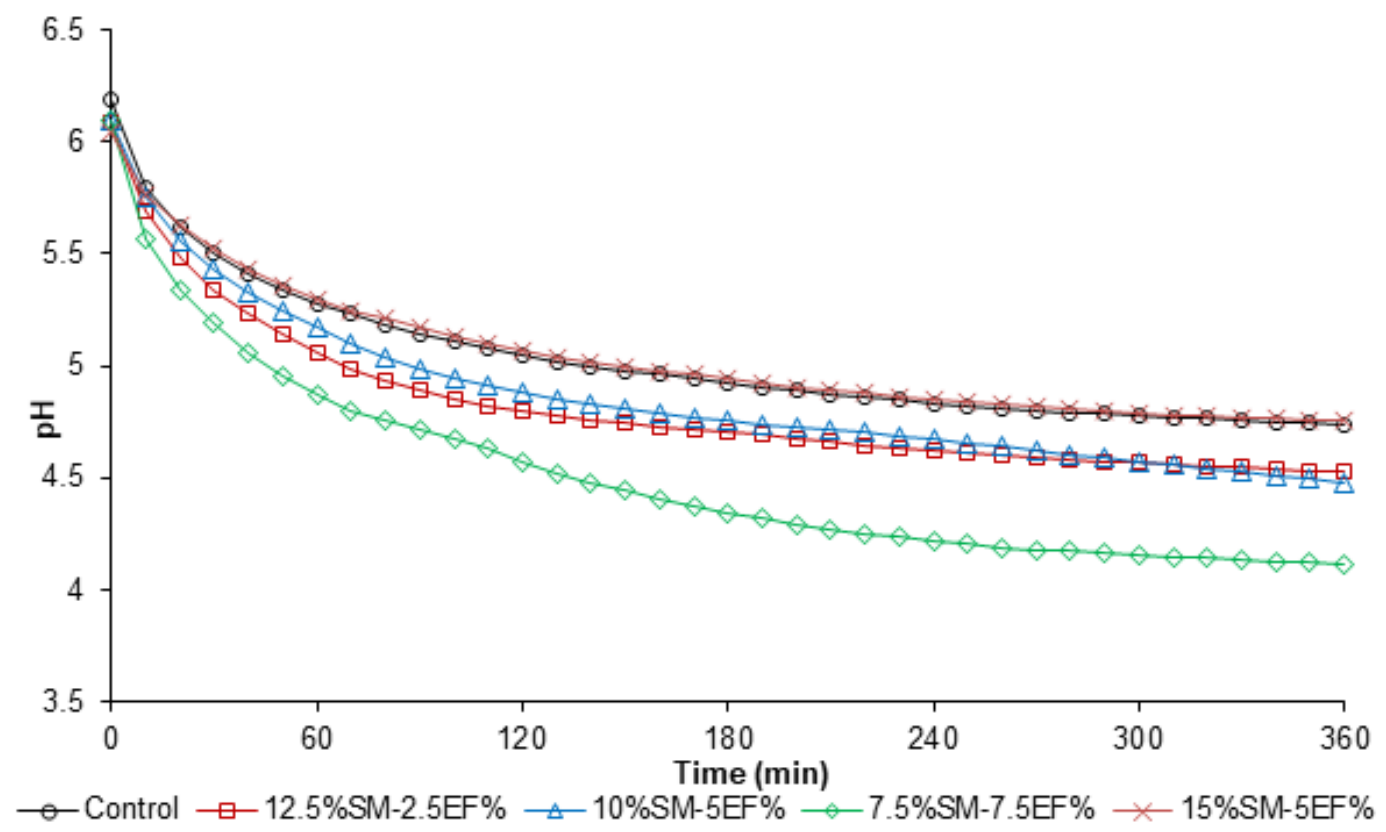

Figure 1. $\mathrm{pH}$ evolution of yogurt like gels containing different percentages of extruded flour

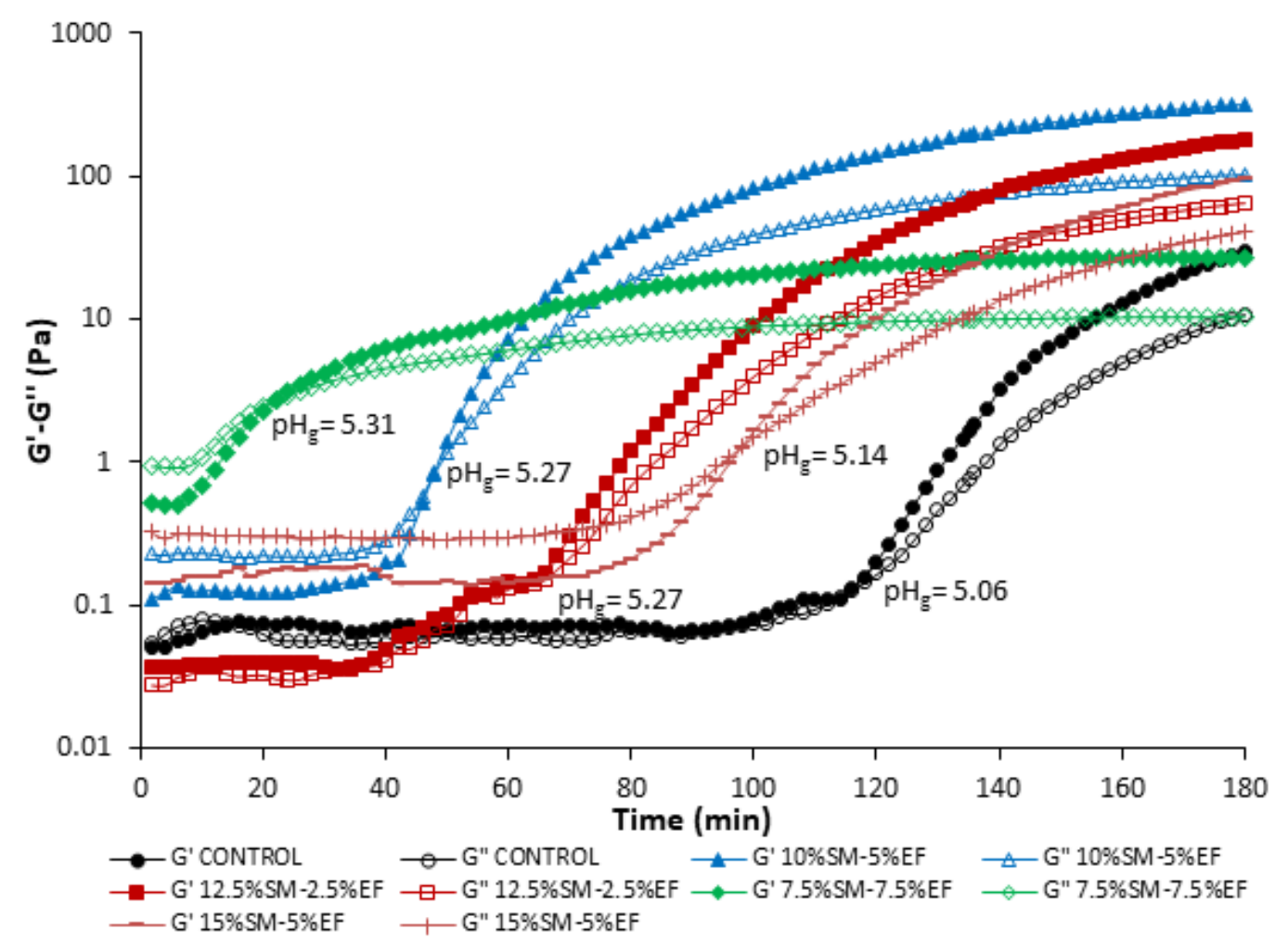

Figure 2. Viscoelastic moduli evolution during acidification of different yogurt based gels made with GDL and different percentages of extruded flour. Filled and empty symbols indicate G' and G" values, respectively. $\mathrm{pHg}$ indicates the $\mathrm{pH}$ at gelation time, calculated as the cross-over between $\mathrm{G}^{\prime}$ and $\mathrm{G}^{\prime \prime}$ values. 


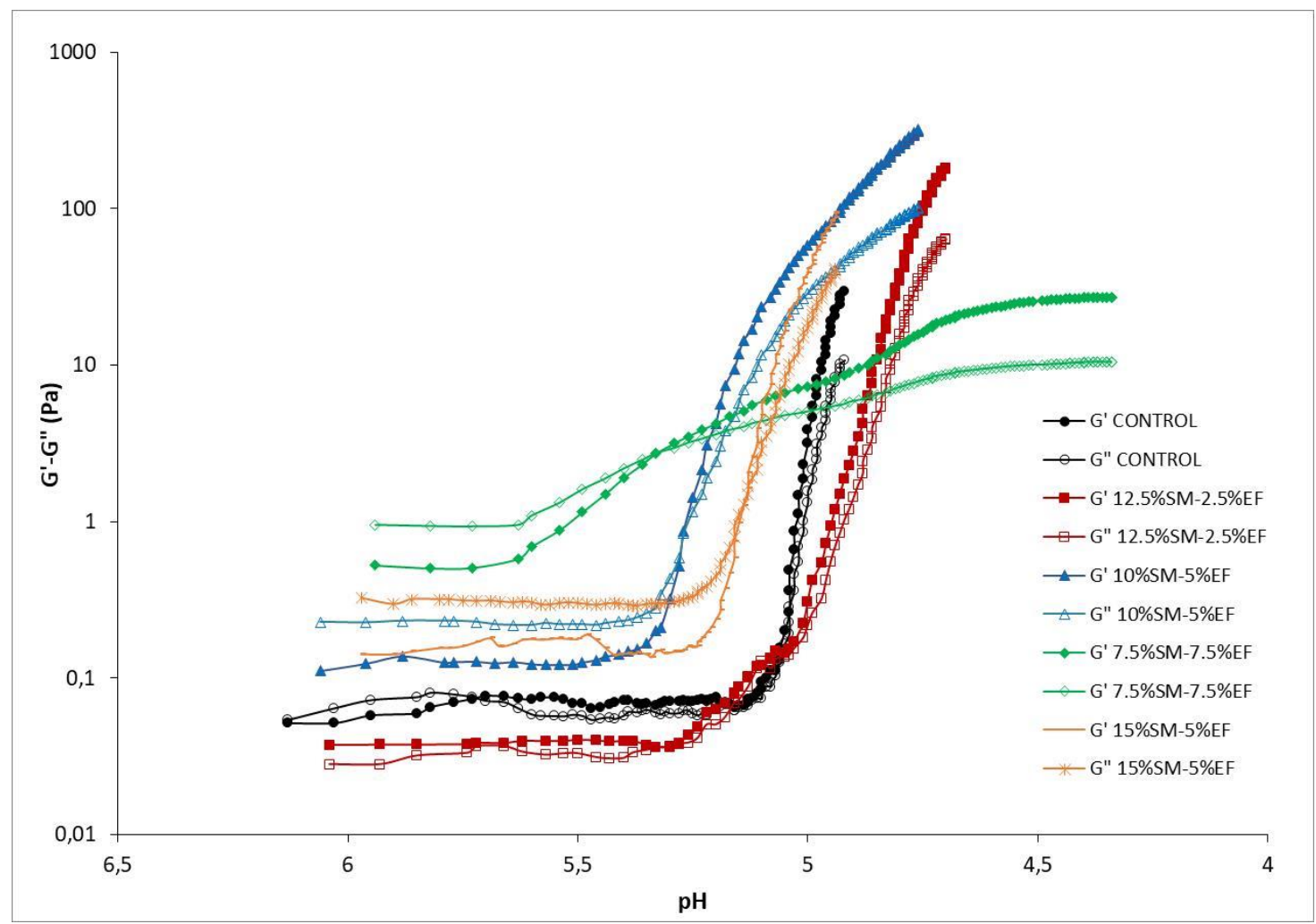

Figure 3. Evolution of viscoelastic moduli with the acidification of milk gels

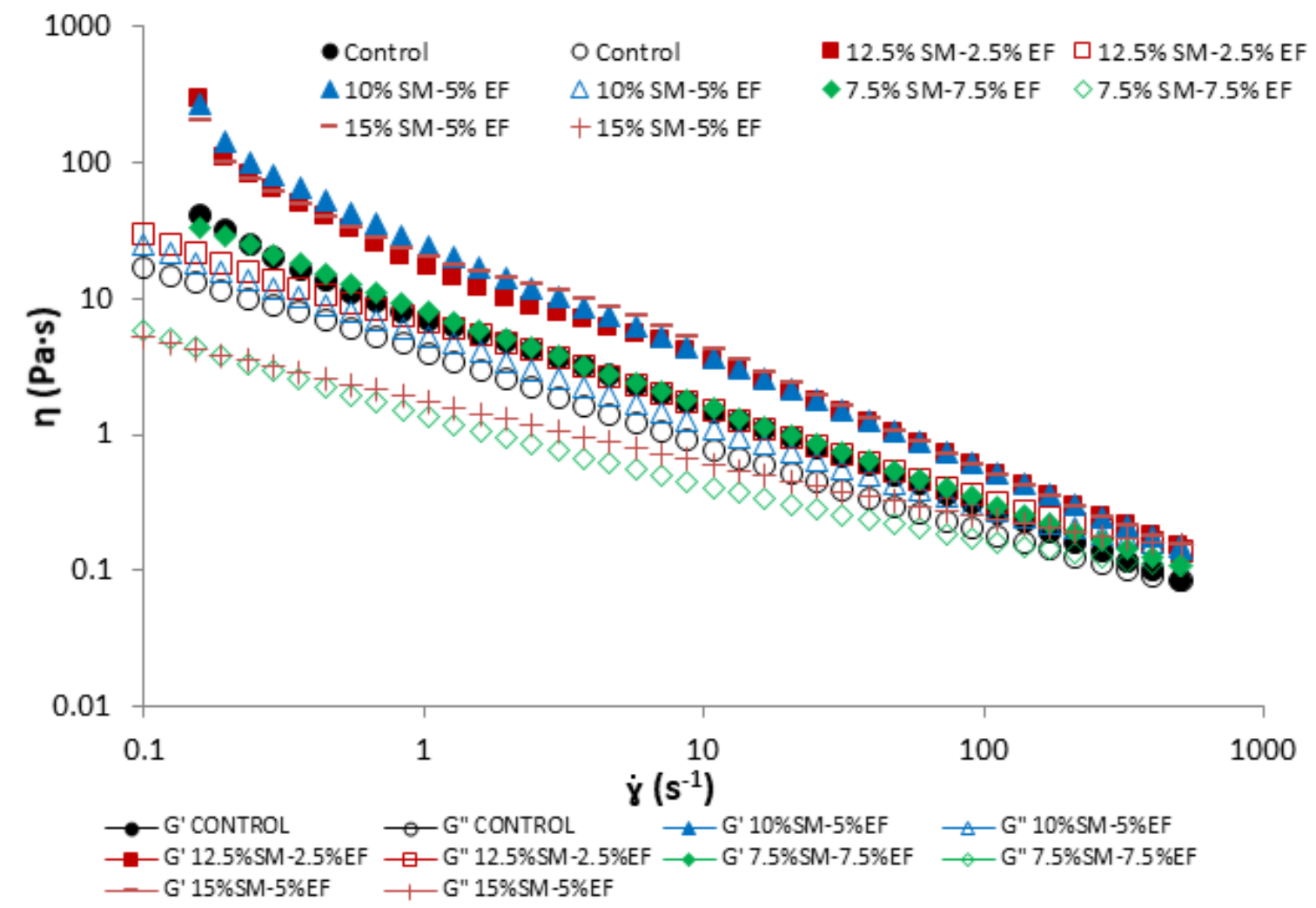

Figure 4. Apparent viscosity of acid stirred gels made with different percentages of extruded flour. Filled and empty symbols indicate up and down shear rate curves, respectively. 

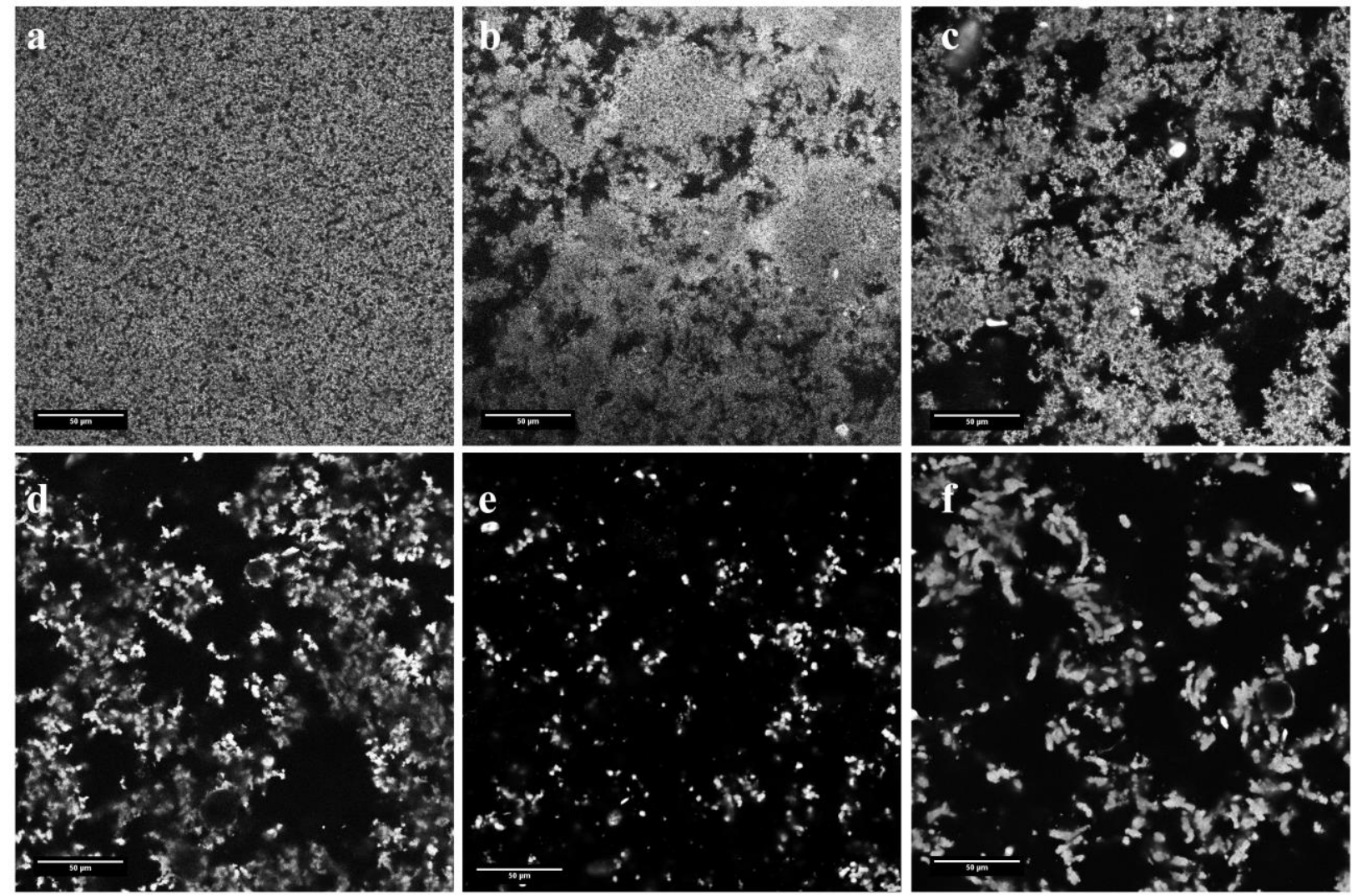

Figure 5. Confocal microscopy images of different set and stirred gels. a, control set gel (15\% SM); b, control stirred gel (15\% SM); c, 12.5\% SM-2.5\% EF stirred gel; d, 10\% SM-5\% EF stirred gel; e, 7.5\% SM-7.5\% EF stirred gel; f, 15\% SM-5\% EF stirred gel. 